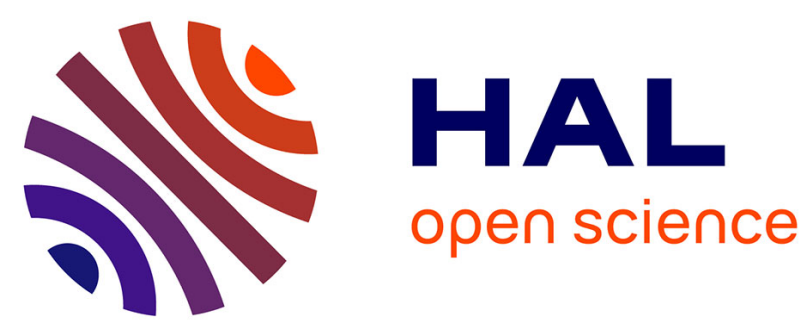

\title{
Electronic and chiroptical properties of chiral cycloiridiated complexes bearing helicenic NHC ligands
} Nora Hellou, Claire Jahier-Diallo, Olivier Baslé, Monika Srebro-Hooper, Loic Toupet, Thierry Roisnel, Elsa Caytan, Christian Roussel, Nicolas Vanthuyne, Jochen Autschbach, et al.

\section{To cite this version:}

Nora Hellou, Claire Jahier-Diallo, Olivier Baslé, Monika Srebro-Hooper, Loic Toupet, et al.. Electronic and chiroptical properties of chiral cycloiridiated complexes bearing helicenic NHC ligands. Chemical Communications, 2016, 52 (59), pp.9243-9246. 10.1039/C6CC04257K . hal-01339910

\section{HAL Id: hal-01339910 \\ https://hal-univ-rennes1.archives-ouvertes.fr/hal-01339910}

Submitted on 30 Jun 2016

HAL is a multi-disciplinary open access archive for the deposit and dissemination of scientific research documents, whether they are published or not. The documents may come from teaching and research institutions in France or abroad, or from public or private research centers.
L'archive ouverte pluridisciplinaire HAL, est destinée au dépôt et à la diffusion de documents scientifiques de niveau recherche, publiés ou non, émanant des établissements d'enseignement et de recherche français ou étrangers, des laboratoires publics ou privés. 


\title{
Electronic and chiroptical properties of chiral cycloiridiated complexes bearing helicenic NHC ligands
}

\author{
Nora Hellou, ${ }^{a}$ Claire Jahier-Diallo, ${ }^{\text {b, }}$ Olivier Baslé, ${ }^{b}$ Monika Srebro-Hooper, ${ }^{c}$ Loïc Toupet, ${ }^{\text {a }}$ Thierry \\ Roisnel, ${ }^{a}$ Elsa Caytan, ${ }^{a}$ Christian Roussel, ${ }^{d}$ Nicolas Vanthuyne, ${ }^{d}$ Jochen Autschbach, ${ }^{*}, \mathrm{e}$ Marc \\ Mauduit, and Jeanne Crassous*,a
}

The first helicene-NHC-iridium complexes have been prepared in enantiopure forms. Their stereochemical, electronic, and chiroptical features were characterized experimentally and via first-principles calculations, highlighting the helical and iridiumcentered chirality.

$\mathrm{N}$-heterocyclic carbene (NHC) transition-metal (TM) complexes have undergone rapid development in the past two decades due to their important applications in catalysis, medicinal chemistry, and molecular materials. ${ }^{1,2}$ Notably, the high structural modularity of NHCs has enabled the design of a large variety of chiral architectures, which gave rise to highly stereoselective organometallic catalysts. ${ }^{3}$ On the other hand, chiral NHC-TM systems may combine optical activity with other desired properties such as emission, electroactivity and high stability, which make them attractive candidates as multifunctional optoelectronic materials. ${ }^{4}$ Nevertheless, studies exploring the chiroptical properties of NHC-based TMcomplexes are still very rare. ${ }^{5}$ Furthermore, while the coordination of helicenic ligands to TM has recently led to organometallic species with unique physico-chemical properties, ${ }^{6,7}$ this approach has never been considered in $\mathrm{NHC}$ chemistry. ${ }^{8}$

This communication describes the preparation of the first cycloiridiated NHC complexes bearing either an achiral [4] helicene (i.e. a benzophenanthrene) or a chiral [6]helicene moiety. In complexes $\mathbf{3 a , b}, \mathbf{b}$ the $\operatorname{Ir}(\mathrm{III})$ is a stereogenic center as well. ${ }^{9}$ The stereochemical features, along with electronic and chiroptical properties, i.e. electronic circular dichroism (ECD) and molar rotation (MR), are examined both experimentally and theoretically.

The two targeted systems are cycloiridiated complexes $(\mathbf{3} \mathbf{a}, \mathbf{b})$ of general formula $(\mathbf{4} \mathbf{a}, \mathbf{b}) \operatorname{IrBrCp} *$ where $\mathrm{Cp}^{*}=$ pentamethylcyclopentadienyl, and $\mathbf{4 a}, \mathbf{b}$ are the LX-type NHC ligands derived from either a [4]helicene- (2a) or a [6]helicenebased unit (2b) grafted at position 2 by a 1-methylene-3-

a. Institut des Sciences Chimiques de Rennes, UMR 6226, Institut de Physique de Rennes, UMR 6251, Campus de Beaulieu, CNRS-Université de Rennes 1, 35042 Rennes Cedex, France.E-mail: jeanne.crassous@univ-rennes1.fr

${ }^{b .}$ Ecole Nationale Supérieure de Chimie de Rennes, CNRS, UMR 6226, 11 Allée de Beaulieu, CS 50837, 35708 Rennes Cedex 7, France.

Department of Theoretical Chemistry, Faculty of Chemistry, Jagiellonian University, R. Ingardena 3, 30-060 Krakow, Poland.

d. Aix Marseille Université, Centrale Marseille, CNRS, iSm2 UMR 7313, 13397, Marseille, France.

e. Department of Chemistry, University at Buffalo, State University of New York, Buffalo, NY 14260, USA. E-mail: jochena@buffalo.edu

f. Present address: CRML Université du Québec, Trois-Rivières, QC, G9A 5H7, Canada Electronic Supplementary Information (ESI) available: [details of any supplementary information available should be included here]. See DOI: $10.1039 / x 0 x x 00000 x$ methylimidazolium bromide (Scheme 1). Imidazolium salt 2a was prepared from 2-bromomethylene[4]helicene ${ }^{10 a}$ 1a by means of nucleophilic substitution with 3-methylimidazolium. The subsequent cyclometallation reaction in refluxing acetonitrile, using $\left[\mathrm{Cp}^{*} \mid \mathrm{ICl}_{2}\right]_{2}$ as the iridium source and a base, such as for instance $\mathrm{NaOAc}$, yielded complex $3 a$ with $57 \%$ yield after crystallization. The crystallization step was necessary to remove the chlorido complex, i.e. (4a) $\mathrm{IrClCp} *$ that is formed in smaller quantities during the reaction. ${ }^{11, \neq}$

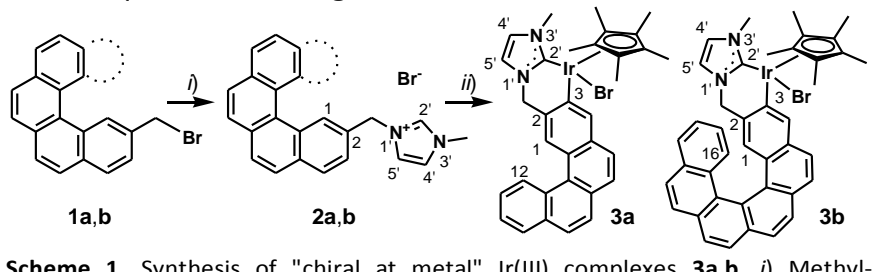
Scheme 1. Synthesis of "chiral at metal" Ir(III) complexes 3a,b. i) Methyl-
imidazole, acetone, reflux, $15 \mathrm{hrs}, 66-71 \%$; ii) $\left[\mathrm{Cp}^{*} \mid \mathrm{rCl}_{2}\right]_{2}, \mathrm{NaOAc}^{\mathrm{C}} \mathrm{CH}_{3} \mathrm{CN}, 80^{\circ} \mathrm{C}, 15$ hrs, $35-57 \%$ after crystallization

Compound 3a was fully characterized by NMR spectroscopy, mass spectrommetry and X-ray crystallography (see Electronic Supporting Information, ESI). For instance, its ${ }^{1} \mathrm{H}$ NMR spectrum displays the typical deshielded $\mathrm{H}^{1}$ and $\mathrm{H}^{12}$ helicenic protons at 8.79 and $9.20 \mathrm{ppm}$ respectively, while the $\mathrm{H}^{2^{\prime}}$ imidazolium and $\mathrm{H}^{3}$-helicene signals have disappeared. The bridging methylene group appears as an $A B$ system around 5 ppm (with a $14 \mathrm{~Hz}$ coupling constant) similarly to analogous cycloiridiated complexes. ${ }^{11}$ Furthermore, two types of methyl groups are observed at 3.97 and $1.76 \mathrm{ppm}$ for the 3'-methylimidazole and the $\mathrm{Cp}^{*}$, respectively.

Racemic complex $3 a$ crystallized in the centro-symmetric $P 2_{1} /$ n space group. X-ray crystallographic studies (Figure 1) revealed that the cyclometallation occurred preferentially at position 3 rather than at position 1 , certainly due to less steric congestion. The $\mathrm{Ir}-\mathrm{C}^{2}$ distance of $1.998 \AA$ is characteristic of an Ir-NHC bond while the $\mathrm{Ir}-\mathrm{C}^{3}$ bond-length of $2.047 \AA$ ascertains that the cyclometallation occurred. ${ }^{11}$ Two stereogenic elements are found in the solid state, i.e. the Ir center and the [4] helicene unit, with only two enantiomeric pairs, i.e. $\left(M, R_{1 \mathrm{r}}\right)$ and $\left(P, S_{\mathrm{Ir}}\right)$. The other diastereomers are not present. The [4] helicene moiety displays a helical angle of $30^{\circ}$. Note, however, that in solution only the stereogenic Ir center is stable since the [4] helicene fragment readily epimerizes (vide infra). The 6-membered iridacycle adopts a boat conformation and $\pi-\pi$ stacking interactions are observed between the $C p^{*}$ and the [4] helicene of two homochiral pairs with the same $\left(P, S_{\mathrm{Ir}}\right)$ or $\left(M, R_{\mathrm{Ir}}\right)$ configurations (see Figure 1$)$. 


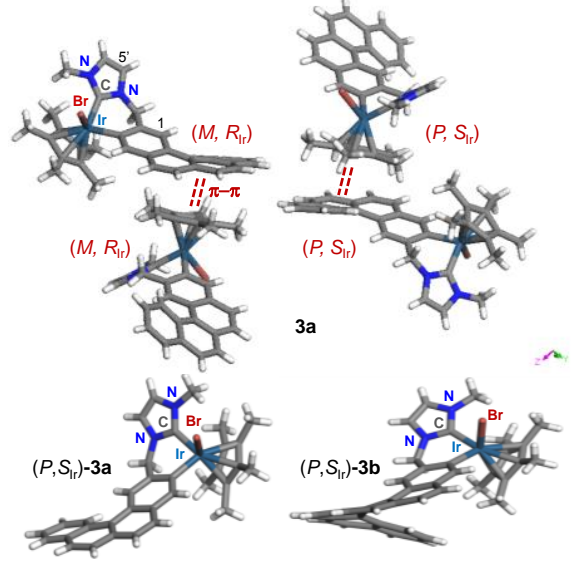

Figure 1. X-ray structure of racemic $\left(M, R_{\mid r}\right) /\left(P, S_{\mid r}\right)-3 a$ and its supramolecular organization. X-ray structure of enantiopure $\left(P, S_{\mathrm{Ir}}\right)-\mathbf{3 a}$ and $\left(P, S_{\mathrm{Ir}}\right)-\mathbf{3 b}$.

The conformational equilibrium of the 6-membered iridacycle was investigated by density functional theory (DFT) calculations (BP functional with a continuum solvent model for $\left.\mathrm{CH}_{2} \mathrm{Cl}_{2}\right)$. For the $\left(P, \mathrm{~S}_{\mathrm{Ir}}\right)$-3a diastereomer, two stable boat-like conformations were found and optimized. However, the conformer with the $\mathrm{CH}_{2}$ group pointing towards $\mathrm{Cp}^{*}$ (as in the XRD structure of Figure 1 ) is significantly lower in energy (by $13.1 \mathrm{kcal} / \mathrm{mol}$ ) than the one with $\mathrm{CH}_{2}$ pointing towards the $\mathrm{Br}$ ligand (see ESI), and therefore latter can be neglected. $\left(P, R_{\mathrm{lr}}\right)$ 3a affords the same strong conformational preference (14.3 $\mathrm{kcal} / \mathrm{mol})$. Furthermore, NOESY experiments showed clear correlation peaks between one methylenic proton and $\mathrm{H}^{1} / \mathrm{H}^{5}$ from helicene / NHC units, respectively, while the other $\mathrm{CH}_{2}$ proton correlates with the $\mathrm{Cp}^{*}$ (see ESI), thus confirming the blocked conformation of the iridacycle.

The enantiomeric resolution of this new type of neutral helicenic "chiral at metal"6c,9,12 $\operatorname{Ir}$ (III) complex was achieved by HPLC over a chiral stationary phase (see ESI). The $R_{\mathrm{Ir}}$ and $S_{\mathrm{Ir}}$ enantiomers of $\mathbf{3 a}$ were obtained with good enantiomeric excesses (ee's of 93 and 96\%, respectively) after separation over the Chiralpak (C) IC column (using heptane/ethanol/chloroform mixture as the eluent at room temperature, r.t.). Kinetic studies, based on the evolution of the ECD at $254 \mathrm{~nm}$ with time at $60^{\circ} \mathrm{C}$ (see ESI, Figure S2, page $\mathrm{S7})$, estimate the racemization barrier of (-)-3a around 110 $\mathrm{kJ} / \mathrm{mol}$ and a half-life time of ca. 2 hours at $62^{\circ} \mathrm{C}$ in chloroform. According to the DFT calculations, $\left(P, S_{\mathrm{Ir}}\right)$ - and $\left(P, R_{\mathrm{Ir}}\right)$-3a have a negligible difference in energy (with a very slight preference for $\left(P, S_{\mathrm{Ir}}\right)$, see $\left.E S I\right)$, indicating that 3a may exist as an equal mixture of both diastereomers. To avoid potential decomposition and partial racemization, the complexes were stored at low temperature and in the dark.

The chiroptical properties (electronic circular dichroism (ECD) and molar rotation (MR) $)^{\S}$ of $R_{\mathrm{Ir}}$ and $S_{\mathrm{Ir}}$-3a were then studied. The two mirror-image ECD spectra are depicted in Figure 2. For example, the $S_{\mathrm{Ir}}$-3a enantiomer displays a positive ECD-active band at $280 \mathrm{~nm}(\Delta \varepsilon=+36)$, two negative ones at $306(\Delta \varepsilon=-18)$ and $360 \mathrm{~nm}(\Delta \varepsilon=-10)$ and a very weak positive one $(\Delta \varepsilon=+7)$ at $413 \mathrm{~nm}$. Overall the ECD of "chiral at $\mid \mathrm{r}^{\prime \prime}$ complex $\mathbf{3 a}$ is relatively weak. The MR is also low $\left(S_{\operatorname{Ir}}-(+)-\mathbf{3 a}\right.$
$\left.\lceil\phi]_{D}^{3}=+230( \pm 7 \%), C 1.810^{-3} \mathrm{M}, \mathrm{CH}_{2} \mathrm{Cl}_{2}\right)$. The $S_{\operatorname{Ir}}-(+)$ and $R_{\operatorname{lr}}-(-)$ absolute configurations were determined by $\mathrm{X}$-ray crystallography of enantiopure (+)-3a which crystallized in the $\mathrm{P} 2{ }_{1} 2_{1} 2_{1}$ space group (Figure 1). Time-dependent DFT (TDDFT, BHLYP / PBEO functional for MR / ECD, $\mathrm{CH}_{2} \mathrm{Cl}_{2}$ solvent model) calculations of the chiroptical properties were also performed. ${ }^{13}$ The Boltzmann-average of the calculated $\left(P, S_{\text {Ir }}\right)$ and $\left(M, S_{\mid r}\right)-3 a$ MRs is 284 and agrees very well with the experiment.

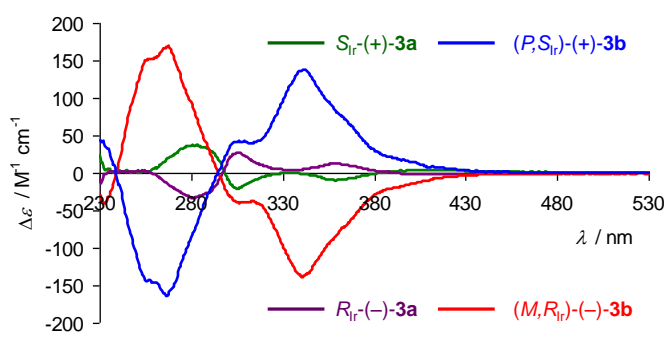

Figure 2. Electronic circular dichroism spectra of complexes $R_{\mathrm{Ir}}$ and $S_{\mathrm{Ir}}$-3a and Figure 2. Electronic circular dichroism spectra of complexes
$\left(P, S_{\text {Ir }}\right)-$ and $\left(M, R_{\mathrm{Ir}}\right)-3 \mathbf{b}$ in $\mathrm{CH}_{2} \mathrm{Cl}_{2}$ at $20^{\circ} \mathrm{C}$. (C $\left.\sim 50^{-5}-210^{-1} \mathrm{M}\right)$

The sign pattern of the experimentally observed ECD bands, and their relative intensities, are also correctly reproduced in the simulated ECD spectrum (see the ESI for the full set of calculated data and spectral analyses). For instance, in the computed spectrum of $S_{\mathrm{Ir}}$-3a, for increasing energy / decreasing wavelength a very weak positive band is followed by two negative bands and a positive one (Figure 3 ). It should be stressed that the simulated ECD spectrum is obtained from an average of optimized structures for the $P$ and $M$ helicities of the ligand, with concomitant cancellation of nearly opposite rotatory strengths. Therefore, the averages are sensitive to the energy difference between the $\left(P, S_{\mid r}\right)-$ and $\left(M, S_{\mid r}\right)-3 a$ stereoisomers, the functional used in the TDDFT computations, and other theoretical details (see ESI). Similar considerations apply to the calculated MR. However, the lowest-energy electronic excitation always appears with positive rotatory strength and is indicative of the configuration around the metal (vide infra). The lowest-energy part of $S_{1 \mathrm{r}}$-3a spectrum results from two excitations (calculated ca. $410 / 380 \mathrm{~nm}$ for no. 1 / 2), with low-magnitude rotatory strengths of opposite sing (+ / - for no. 1/2). According to a molecular orbital (MO) decomposition of the spectra, the dominant contributions to these excitations arise from from HOMO - LUMO+2 and HOMO-1 - LUMO+2 orbital pairs. These orbitals are centered at and around the metal, which rationalizes why the excitations are influenced by the absolute configuration around Ir. The excitations represent a mixture of ligand-field (LF) as well as ligand-to-metal (LM) and ML charge-transfer (CT) character. Overall, the theoretical analysis highlights the role of the metal center and the carbene-helicene moiety in determining optical activity of these novel compounds. 


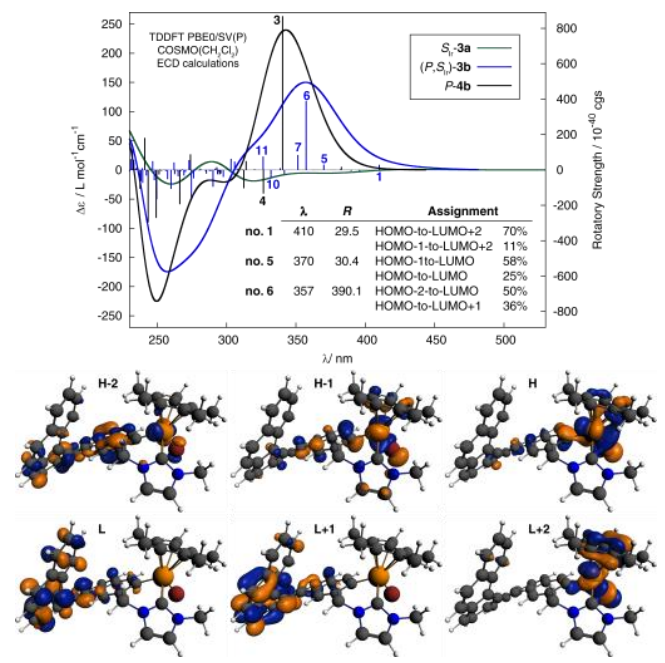

Figure 3. Top: Comparison of the simulated ECD spectra of the Ir-based NHC helicene complex $S_{1 r}-3 a$, of the complex $\left(P, S_{1 r}\right)-3 b$ and its parent $\mathrm{NHC}$-helicene ligand $P$-4b. No spectral shift has been applied. Calculated excitation energies and rotatory strengths indicated as 'stick' spectra. Numbered excitation occupied-to-unoccupied MO pair contributions of the $\left(P, S_{1 r}\right)-3 b$. Wavelength $\lambda$ in

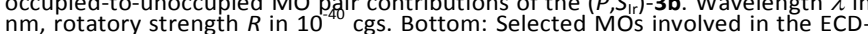
active bands of $\mathbf{3 b}$. See also ESI.

In order to obtain a configurationally stable helicene derivative, the [6]helicene-based methylimidazolium bromide $\mathbf{2 b}$ was prepared from 2-bromomethylene[6]helicene ${ }^{10 b} \mathbf{1 b}$ (Scheme 1). The $\operatorname{Ir}(\mathrm{III})$ complex $\mathbf{3 b}$ was synthesized from $\mathbf{2 b}$ under similar conditions as $\mathbf{3 a}$, and obtained in $35 \%$ isolated yield. Here again, a crystallization step was required to remove the chlorido complex (4b) IrClCp*. Cycloiridiated complex $\mathbf{3 b}$ was fully characterized and ${ }^{1} \mathrm{H}$ NMR analyses showed the same general characteristics as 3a (ESI) with a typical shielded $\mathrm{H}^{1}$ and $\mathrm{H}^{16}$ protons of the [6] helicene core (at 7.15 and $7.84 \mathrm{ppm}$, respectively). In addition, the NMR evidenced only one diastereoisomer which was further identified by X-ray studies as $\left(P, S_{\mathrm{Ir}}\right) /\left(M, R_{\mathrm{Ir}}\right)$-3b. Furthermore, upon crystallization from a $\mathrm{CH}_{2} \mathrm{Cl}_{2}$ /pentane mixture, racemic complex $\mathbf{3 b}$ spontaneously resolved into homochiral crystals $\left(P 2_{1} 2_{1} 2_{1}\right.$ space group). The cyclometallation occurred again at the less hindered position 3 and the $\operatorname{Ir}-\mathrm{C}^{2^{\prime}}(2.016 \AA)$ and $\operatorname{Ir}-\mathrm{C}^{3}(2.064 \AA)$ bond-lengths are characteristic of an Ir-NHC cyclometallated complex. ${ }^{11}$ The [6] helicene unit displays a helical angle of $50^{\circ}$, a typical value for configurationally stable [6] helicene derivatives. ${ }^{6,7}$ Similarly to $3 a$, the 6-membered iridacycle adopts a stable boat-like conformation with different correlation peaks for the two $\mathrm{CH}_{2}$ protons in the ROESY spectrum (see ESI), confirming the presence of one blocked conformation of the iridacycle. Calculations corroborate this finding with an energetic preference of the conformation with $\mathrm{CH}_{2}$ group pointing towards $\mathrm{Cp}^{*}$ by ca. $14 \mathrm{kcal} / \mathrm{mol}$ (see ESI).

Since the crystals were too small to achieve Pasteur's resolution by picking enantiopure crystals manually, the chiral HPLC resolution was carried out. Enantioenriched samples (ee's 92-97\%) were obtained by using the Chiralpak@IE column (see ESI for conditions)." The chiroptical properties $(E C D \text { and } M R)^{\S}$ of enantioenriched $\mathbf{3 b}$ samples were then studied. Figure 2 shows mirror-image spectra in $\mathrm{CH}_{2} \mathrm{Cl}_{2}$ corresponding to $\left(M, R_{\mathrm{Ir}}\right)-$ and $\left(P, S_{\mathrm{Ir}}\right)-\mathbf{3 b}$. Complex $\left(P, S_{\mathrm{Ir}}\right)-\mathbf{3 b}$ displays the typical strong negative ECD band at $266 \mathrm{~nm}(\Delta \varepsilon=-$ 164) accompanied by a shoulder at $254 \mathrm{~nm}(\Delta \varepsilon=-151)$, a strong positive ECD-active band at $340 \mathrm{~nm}(\Delta \varepsilon=+136)$ with a shoulder at $362 \mathrm{~nm}(\Delta \varepsilon=+75)$ and a weaker positive band at $304 \mathrm{~nm}(\Delta \varepsilon=+40)$. Overall the ECD intensity of the chiral Ir complex $\mathbf{3} \mathbf{b}$ is strong, as are its optical rotation values $\left(\left(P, S_{\mathrm{Ir}}\right)\right.$ 3b: $[\alpha]_{D}^{23}=+1490,[\phi]_{D}^{3}=+12350( \pm 5 \%), C 1.110^{-4} \mathrm{M}, \mathrm{CH}_{2} \mathrm{Cl}_{2}$; calc. BHLYP: 13409). The question arose whether the $\left(M, R_{\mathrm{rr}}\right)$ and $\left(P, S_{\mid r}\right)-\mathbf{3 b}$ stereoisomers were the only species present in solution, i.e. whether the stereogenic Ir center in $\mathbf{3 b}$ is configurationally stable. First of all, only one set of signals was observed in the ${ }^{1} \mathrm{H}$ and ${ }^{13} \mathrm{C}$ NMR spectra as well as in the chiral HPLC chromatograms (see ESI). Furthermore, a sample of $\left(M, R_{\mathrm{Ir}}\right)$-3b was heated in refluxing chloroform for $2 \mathrm{hrs}$ and the NMR showed no difference, suggesting that the compound is both diastereoselectively and chemically stable under these conditions (see Figure S11). ${ }^{f}$ Accordingly, the configuration around the $\operatorname{Ir}(\mathrm{III})$ center in $\mathbf{3} \mathbf{b}$ is more stable than in $\mathbf{3 a}$. Note also that the $\left(P, S_{I r}\right)$-3b stereoisomer was calculated to be 1 $\mathrm{kcal} / \mathrm{mol}$ lower in energy than the corresponding $\left(P, R_{\mathrm{Ir}}\right)$ system, which may translate into a $85 / 15$ Boltzmann ratio in favor of $\left(P, S_{\text {Ir }}\right)$ at $20^{\circ} \mathrm{C}$. The experimental observations suggest strongly, however, that the formation and stability of the complexes is dictated by kinetics. Finally, the calculated chiroptical properties of $\left(P, S_{\mid r}\right)-\mathbf{3 b}$ agree very well with experiment (Figure 3$)$; the $\left(P, R_{\mathrm{lr}}\right)$-3b spectrum appears similar but is somewhat more intense (ESI). The energy and assignment of the very first calculated excitation are the same for both $\left(P, S_{\mathrm{Ir}}\right)-/\left(P, R_{\mathrm{Ir}}\right)-\mathbf{3 b}$ and $S_{\mathrm{Ir}}-/ R_{\mathrm{Ir}}-\mathbf{3 a}$. For the $S_{\mathrm{Ir}}\left(R_{\mathrm{Ir}}\right)$ configuration it has positive (negative) rotatory strength, which may additionally support the $\mathbf{3 a}$ configuration assignment. A corresponding weak band or shoulder in the broadened simulated or the experimental ECD spectrum is not visible for $\left(P, S_{\mid r}\right)-/\left(P, R_{\mid r}\right)-3 \mathbf{b}$, however, because the first excitation is over-powered by very intense higher excitations. An MO-pair analysis of the intense excitations of $\left(P, S_{\mid r}\right)-\mathbf{3 b}$ reveals a strong involvement of the $\operatorname{Ir}(\mathrm{III})$ orbitals and carbenic $\pi$-system in the ECD-active transitions. For example, the $\left(P, S_{\mathrm{Ir}}\right)$ 3b excitation with the strongest rotatory strength (no. 6, see inset of Figure 3) affords contributions from the HOMO-2LUMO pair, which corresponds to a helicene $\pi-\pi^{*}$ transition enhanced by the involvement of metal $5 \mathrm{~d}$ orbitals, and from the HOMO-LUMO+1 pair, which has predominantly $\mathrm{ML}$ and ligand-to-ligand (LL) CT character. Two other excitations of moderate intensity, no. 5 and no. 1 are assigned as a mixture of ML/LL CT and LF transitions with some $L M$ and ML CT and clearly involve the carbenic $\pi$-system. These excitations are responsible for the pronounced low-energy tail of the ECD spectrum of $\mathbf{3 b}$. These results account for the noticeable differences between the calculated spectrum of $\left(P, S_{1 r}\right)-3 \mathbf{b}$ versus that of the NHC-helicene ligand $P-\mathbf{4 b}$; the latter essentially affords pure $\pi-\pi^{*}$ helicene character (see ESI). Overall, the spectral analysis shows that the 6-membered iridacycle affords electronic coupling between the metal center and the helicenic NHC ligand. To our knowledge this is the first time that the NHC involvement in the chiroptical 
properties is identified in a chiral NHC transition metal complex.

In conclusion, we have prepared and characterized the first chiral complexes bearing a NHC-helicene ligand. These Ir(III) systems are also chiral at the metal and display efficient chiral induction from the helicene to the iridium center in the case of the NHC-[6] helicene ligand, thus giving access to complexes of well-defined stereochemistry, $\left(M, R_{\mathrm{Ir}}\right)-(-)$ and $\left(P, S_{\mathrm{Ir}}\right)-(+)-3 \mathbf{b}$. In addition, we have shown substantial involvement of occupied MOs with electron density in the NHC group in the transitions causing the electronic circular dichroism. The use of these unprecedented Ir complexes as chiral materials and as enantioselective catalysts is under investigation. Finally, this study, combining $\mathrm{N}$-heterocyclic carbenes, helicenes, and chiral systems chemistry, opens up a new field of research since many different helicene-NHC-based chiral complexes may be targeted.

\section{Aknowledgements}

We acknowledge the Ministère de l'Education Nationale, de la Recherche et de la Technologie, the Centre National de la Recherche Scientifique (CNRS), the ANR (12-BS07-0004METALHEL-01), for financial support. J. A. thanks the National Science Foundation (CHE 1265833) for financial support and the Center for Computational Research (CCR) at the University at Buffalo for computational resources. M. S.-H. acknowledges an 'Outstanding Young Scientist' scholarship and young researchers' T-subsidy from the Ministry of Science and Higher Education in Poland.

\section{Notes and references}

\# Shoulders are present in the HPLC chromatograms and probably account for the presence of some residual isostructural (4a/4b)IrClCp* impurity, that is also seen by mass spectrometry (see ESI).

$f$ The crude NMR of pure racemic $(\mathbf{4 b}) \mathrm{IrClCp} *$, prepared from the chloride salt of $\mathbf{2} \mathbf{b}$, suggests that the reaction was diastereoselective.

$\S$ All $\Delta \varepsilon$ values in this work are given in units of $\mathrm{M}^{-1} \mathrm{~cm}^{-1}$, all specific rotations in degree $\left[\mathrm{dm}\left(\mathrm{g} \mathrm{cm}^{-3}\right)\right]^{-1}$, and all molar rotations in degree $\mathrm{cm}^{2} \mathrm{dmol}^{-1}$.

\# It is not feasible to first generate the carbene $\mathbf{4 b}$ and resolve it into its pure enantiomers, since the free $\mathbf{4 b}$ is expected to be unstable.

1 S. Díez-González (Ed.), N-Heterocyclic Carbenes: From Laboratory Curiosities to Efficient Synthetic Tools; RSC: Cambridge, UK; 2011

2 Selected reviews: a) M. N. Hopkinson, C. Richter, M. Schedler, F. Glorius, Nature 2014, 510, 485; b) D. Bourissou, O. Guerret, F. P. Gabbai, G. Bertrand, Chem. Rev. 2000, 100, 39; c) S. Bellemin-Laponnaz, S. Dagorne, Chem. Rev. 2014, 114, 8747; d) A. Gautier, F. Cisnetti, Metallomics 2012, 4, 23; e) K. M. Hindi, M. J. Panzner, C. A. Tessier, C. L. Cannon, W. J. Youngs, Chem. Rev. 2009, 109, 3859; f) R. Visbal, M. C. Gimeno, Chem. Soc. Rev. 2014, 43, 3551.

3 Selected reviews on chiral NHCs: a) V. César, S. BelleminLaponnaz, L. H. Gade, Chem. Soc. Rev. 2004, 33, 619; b) F.
Wang, L.-J. Liu, W. Wang, S. Li, M. Shi, Coord. Chem. Rev. 2012, 256, 804

4 Selected: a) H. M. J. Wang, C. Y. L. Chen, I. J. B. Lin, Organometallics 1999, 18, 1216; b) Z. M. Hudson, C. Sun, M. G. Helander, Y.-L. Chang, Z.-H. Lu, S. Wang, J. Am. Chem. Soc. 2012, 134, 13930; c) Y. Zhou, J. Jia, W. Li, H. Fei, M. Zhou, Chem. Comm. 2013, 49, 3230; d) M. Nussbaum, O. Schuster, M. Albrecht, Chem. Eur. J. 2013, 19, 17517; e) J. Lee, H.-F. Chen, T. Batagoda, C. Coburn, P. I. Djurovich, M. E. Thompson, S. R. Forrest, Nature Mater. 2016, 15, 92.

5 a) C. Carcedo, J. C. Knight, S. J. A. Pope, I. A. Fallis, A. Dervisi, Organometallics 2011, 30, 2553.

6 Selected recent reviews: a) Y. Shen, C. -F. Chen, Chem. Rev. 2012, 112, 1463; b) M. Gingras, Chem. Soc. Rev. 2013, 42, 1051; c) N. Saleh, C. Shen, J. Crassous, Chem. Sci. 2014, 5, 3680 and references therein; d) H. Isla, J. Crassous, Comptes Rendus Chimie 2016, 19, 39.

7 Selected examples: a) E. Anger, M. Rudolph, C. Shen, N. Vanthuyne, L. Toupet, C. Roussel, J. Autschbach, J. Crassous, R. Réau, J. Am. Chem. Soc. 2011, 133, 3800; b) C. Shen, E. Anger, M. Srebro, N. Vanthuyne, K. K. Deol, T. D. Jefferson Jr., G. Muller, J. A. G. Williams, L. Toupet, C. Roussel, J. Autschbach, R. Réau, J. Crassous, Chem. Sci. 2014, 5, 1915; c) E. Anger, M. Srebro, N. Vanthuyne, L. Toupet, S. Rigaut, C. Roussel, J. Autschbach, J. Crassous, R. Réau, J. Am. Chem. Soc. 2012, 134, 15628; d) D. Mendola, N. Saleh, N. Vanthuyne, C. Roussel, L. Toupet, F. Castiglione, T. Caronna, A. Mele, J. Crassous, Angew. Chem. Int. Ed. 2014, 53, 5786; e) N. Saleh, M. Srebro, T. Reynaldo, N. Vanthuyne, L. Toupet, V. Y. Chang, G. Muller, J. A. G. Williams, C. Roussel, J. Autschbach, J. Crassous, Chem. Comm. 2015, 51, 3754; f) C. Shen, G. Loas, M. Srebro-Hooper, N. Vanthuyne, L. Toupet, O. Cador, F. Paul, J. T. López Navarrete, F. J. Ramírez, B. Nieto-Ortega, J. Casado, J. Autschbach, M. Vallet, J. Crassous, Angew. Chem. Int. Ed. 2016, accepted.

8 For an example of helicene-carbene-osmium see: E. Anger, M. Srebro, N. Vanthuyne, C. Roussel, L. Toupet, J. Autschbach, R. Réau, J. Crassous, Chem. Comm. 2014, 50, 2854.

9 a) A. von Zelewsky, Stereochemistry of Coordination Compounds, J. Wiley \& Sons, Chichester, 1996; b) V. I. Sokolov, Chirality and Optical Activity in Organometallic Compounds, Gordon \& Breach Science Publishers, New York, 1990; c) A. Amouri, M. Gruselle, Chirality in Transition Metal Chemistry: Molecules, Supramolecular Assemblies and Materials, Wiley-VCH, 2009.

10 a) D. A. Lightner, T. W. Powers, G. W. Frank, F. N. Trueblood, D. T. Hefelfinger, J. Am. Chem. Soc. 1972, 94, 3492; b) J. Storch, J. Zadny, T. Strasak, M. Kubala, J. Sykora, M. Dusek, V. Cirkva, P. Matejka, M. Krbal, J. Vacek, Chem. Eur. J. 2015, 21, 2343

11 a) R. Corberán, M. Sanaú, E. Peris, J. Am. Chem. Soc. 2006, 128, 3974; b) X. -H. Zhu, L. -H. Cai, C. -X. Wang, Y. -N. Wang, X. -Q. Guo, X. -F. Hou, J. Mol. Cat. A 2014, 393, 134.

12 a) E. B. Bauer, Chem. Soc. Rev. 2012, 41, 3153; b) E. C. Constable, Chem. Soc. Rev. 2013, 42, 1637.

13 a) J. Autschbach, Chirality 2009, 21, E116; b) J. Autschbach, L. Nitsch-Velasquez, M. Rudolph, Top. Curr. Chem. 2011, 298, 1. 